\title{
The Xylella fastidosa RTX operons: evidence for the evolution of protein mosaics through novel genetic exchanges
}

\author{
Gregory A. Gambetta ${ }^{1 *}$, Mark A. Matthews ${ }^{2}$ and Michael Syvanen ${ }^{3}$
}

\begin{abstract}
Background: Xylella fastidiosa (Xf) is a gram negative bacterium inhabiting the plant vascular system. In most species this bacterium lives as a benign symbiote, but in several agriculturally important plants (e.g. coffee, citrus, grapevine) $X f$ is pathogenic. Xf has four loci encoding homologues to hemolysin RTX proteins, virulence factors involved in a wide range of plant pathogen interactions.

Results: We show that all four genes are expressed during pathogenesis in grapevine. The sequences from these four genes have a complex repetitive structure. At the C-termini, sequence diversity between strains is what would be expected from orthologous genes. However, within strains there is no N-terminal homology, indicating these loci encode RTXs of different functions and/or specificities. More striking is that many of the orthologous loci between strains share this extreme variation at the N-termini. Thus these RTX orthologues are most easily visualized as fusions between the orthologous $\mathrm{C}$-termini and different $\mathrm{N}$-termini. Further, the four genes are found in operons having a peculiar structure with an extensively duplicated module encoding a small protein with homology to the $\mathrm{N}$-terminal region of the full length RTX. Surprisingly, some of these small peptides are most similar not to their corresponding full length RTX, but to the N-termini of RTXs from other Xf strains, and even other remotely related species.

Conclusions: These results demonstrate that these genes are expressed in planta during pathogenesis. Their structure suggests extensive evolutionary restructuring through horizontal gene transfers and heterologous recombination mechanisms. The sum of the evidence suggests these repetitive modules are a novel kind of mobile genetic element.
\end{abstract}

Keywords: Hemolysin, Pierce's disease, Horizontal gene transfer, Lateral gene transfer, Orphan

\section{Background}

One of the goals of whole genome analysis of pathogenic bacteria is to identify novel genes encoding potential pathogenicity factors [1-3]. A reasonable approach is to compare the sequence of a pathogenic bacteria to a nonpathogenic relative [4] as illustrated by the complete sequencing and subsequent comparisons of several different strains of Xylella fastidosa $(X f)$ with different host-specificities, levels of virulence, etc. [5-9]. In general, this approach has run into the difficulty that two

\footnotetext{
* Correspondence: gregory.gambetta@agro-bordeaux.fr

${ }^{1}$ Bordeaux Science Agro, Institut des Sciences de la Vigne et du Vin, Ecophysiologie et Génomique Fonctionnelle de la Vigne, UMR 1287, F33140 Villenave d'Ornon, France

Full list of author information is available at the end of the article
}

closely related strains from the same species can have differences in a large number of genes, many of which are unrelated to pathogenesis $[5,6]$. In this work we have taken a different approach, comparing genes previously characterized as pathogenicity factors, focusing on those homologues with unusual divergence patterns across $X f$ strains.

$X f$ is an extremely fastidious gamma proteobacterium found only in the water conducting vascular system of diverse plant species. In most species $X f$ lives as a benign symbiote, but in several agriculturally important plants such as coffee, citrus, and grape, $X f$ is pathogenic [10]. In these susceptible plant species infection leads to leaf scorch, premature leaf senescence, reduced vigor, and crop loss. Mechanisms of its pathogenesis remain largely

(c) The Author(s). 2018 Open Access This article is distributed under the terms of the Creative Commons Attribution 4.0 International License (http://creativecommons.org/licenses/by/4.0/), which permits unrestricted use, distribution, and 
unknown. Originally, pathogenesis was thought to result from simple occlusion of the water conducting vascular system [11, 12], though other studies point towards a more nuanced mechanism where pathogenesis results from specific $X f$ pathogenicity factors and the induced plant defense response [13-15].

Based on comparative genome analysis our attention was drawn to a $X f$ gene family that encodes homologs of the $E$. coli hemolysins, members of the RTX protein family $[16,17]$. RTXs are found in many bacterial human pathogens and are well established pathogenicity factors, appearing in surprisingly diverse disease processes. In animals, they are thought to disrupt host cell function leading to cytolysis through the formation of trans-membrane pores, but a variety of other functions have also been characterized in RTXs, including perturbing $\mathrm{Ca}^{++}$signaling [18] and disruption of the cytoskeleton [19]. Such diverse functions should not be surprising given that in many cases RTXs actually represent protein mosaics, containing the conserved RTX domain that defines this protein family along with other functional domains of both known and unknown functions.

RTXs are also present in numerous plant pathogens and there is evidence for their role in plant disease [20] and in leaf lesion formation specifically [21]. In Xf, RTX-like adhesins have been implicated in pathogenesis [22-24]. Other RTXs have been hypothesized to play a role in $X f$ pathogenesis, although their expression has not been reported in planta. Xf 9a5c has been shown to produce and excrete two RTXs (RTX1 and RTX2 in this study) in culture [25], and whole genome comparisons of 9a5c with a nonpathogenic strain (J1a12) revealed that an RTX (RTX1) is among only 50 genes that are divergent in the nonpathogenic strain [8]. In addition, mutations in $X f$ 's type-I secretion system (via mutation of TolC), responsible for the secretion of RTXs, was shown to be essential for $X f$ survival in planta [26], although this interpretation is equivocal given the numerous proteins secreted via a TolC dependent pathway [27]. Taken together these results suggest a role for these loci in pathogenesis.

In this study we report gene expression analyses during Pierce's disease (PD) in grapevine and comparative genomic analyses across $X f$ strains with specific host specificities; those causing Pierce's disease in grapevine (Temecula), citrus variegated chlorosis $(9 \mathrm{a} 5 \mathrm{c})[9,28]$, almond leaf scorch (Dixon), and oleander leaf scorch (Ann1) [5, 6].

\section{Methods}

\section{Operon sequences}

The four putative RTX operon sequences analyzed from $X f$ strains causing Pierce's disease in grapevine (Temecula), citrus variegated chlorosis (9a5c), almond leaf scorch (Dixon), and oleander leaf scorch (Ann1), were obtained through NCBI. The genomic sequence accession numbers for Temecula, 9a5c, Dixon, and Ann1, are AE009442, AE003849, AAAL02000001, AAAM03000044, respectively. The NCBI protein accession numbers and locus tags for each operon's RTX can be found in Additional file 1: Table S1.

\section{$X f$ infected plant material}

Field samples were obtained from a commercial vineyard of Chardonnay grapevines (Beringer Vineyards, Yountville, CA, USA). Early in the growing season (May-July) plants were identified that exhibited typical Pierce's disease symptoms; shriveled fruit, leaf-scorch, petiole matchsticks, etc. Eight plants were selected and 10 leaves from each plant were harvested and homogenized. Total DNA was isolated and the presence of $X f$ bacteria was confirmed by PCR [13]. In August, from these plants 14 leaves exhibiting various severities of leaf scorch, and 4 leaves from healthy controls, were excised, immediately frozen in dry ice, transported from the field to the lab, and placed at $-80^{\circ} \mathrm{C}$.

\section{RNA preparation and $\mathrm{qPCR}$ analyses}

Each leaf was homogenized under liquid nitrogen. Immediately, total RNA was extracted from $0.3 \mathrm{~g}$ of tissue following the procedure described in Iandolino et al. (2004) and treated with $0.5 \mathrm{U} / \mu \mathrm{g}$ RQ1 DNase (Promega). First strand cDNA was synthesized using $2 \mu \mathrm{g}$ of RNA, $0.5 \mu \mathrm{M}(\mathrm{dT}) 18$ primer, and $50 \mathrm{U}$ of M-MLV Reverse Transcriptase (Promega).

The following primer pairs were designed to amplify an approximately $100 \mathrm{bp}$ fragment of each individual Temecula RTX gene: RTX1, forward 5'-gaaagactggttgactgccgagg- 3 ' and reverse 5 '-gaccccggaaaccttgagcagcat3'; RTX2, forward 5'-aacggccggaacatcctggttgga-3' and reverse 5'-caggggcaacgatatgctctacgg-3'; RTX3, forward $5^{\prime}$-aatacgctcactcgattcgcc- $3^{\prime}$ and reverse 5 '-gcagcctgtcagaaattgtc-3'; RTX4, forward 5' -ggagatttgaatgagatacgc-3' and reverse $5^{\prime}$-gggaaggattccgcaagtagc- $3^{\prime}$. As a positive control, the primer pairs were first tested by amplifying the fragment from total $X f$ (Temecula) genomic DNA. Briefly, $X f$ (Temecula) was grown in culture and genomic DNA was isolated using a DNeasy Tissue Mini Kit (Qiagen, Inc.) following the manufacturer's protocol. Fragments were amplified in a $20 \mu \mathrm{L}$ reaction volume including $1 \times$ buffer, $1.5 \mathrm{mM} \mathrm{MgCl}, 200 \mu \mathrm{M}$ dNTPs, $250 \mathrm{nM}$ of each primer, 2.5 units Taq polymerase, and approximately $100 \mathrm{ng} X f$ genomic DNA. The cycling conditions were as follows: $95{ }^{\circ} \mathrm{C}$ for $10 \mathrm{~min}, 30$ cycles of $95{ }^{\circ} \mathrm{C}$ for $30 \mathrm{~s}, 60{ }^{\circ} \mathrm{C}$ for $30 \mathrm{~s}$, and $72{ }^{\circ} \mathrm{C}$ for $1 \mathrm{~min}$, followed by $72{ }^{\circ} \mathrm{C}$ for $5 \mathrm{~min}$.

Quantitative real-time PCR was carried out in an ABI PRISM 7500 fast sequence detector (Applied Biosystems). Standard curves were produced for each RTX gene by diluting known concentrations of $X f$ to obtain a 


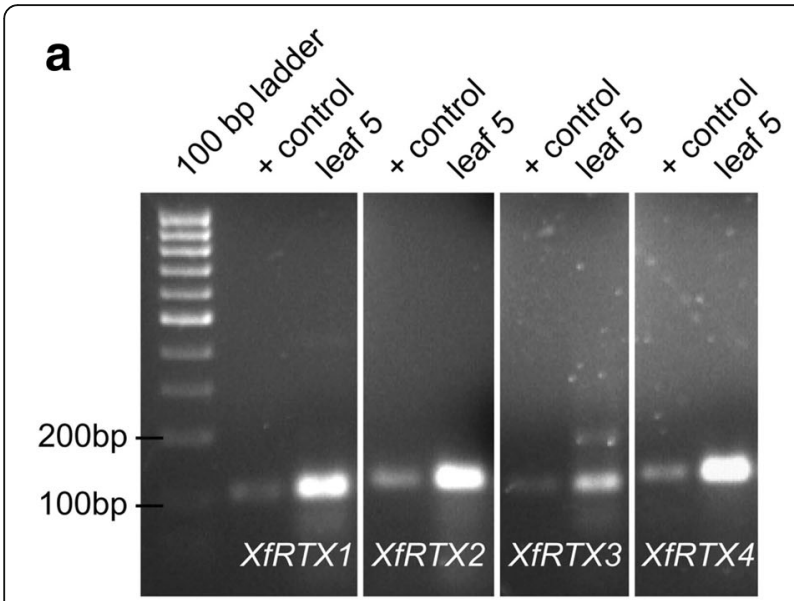

b

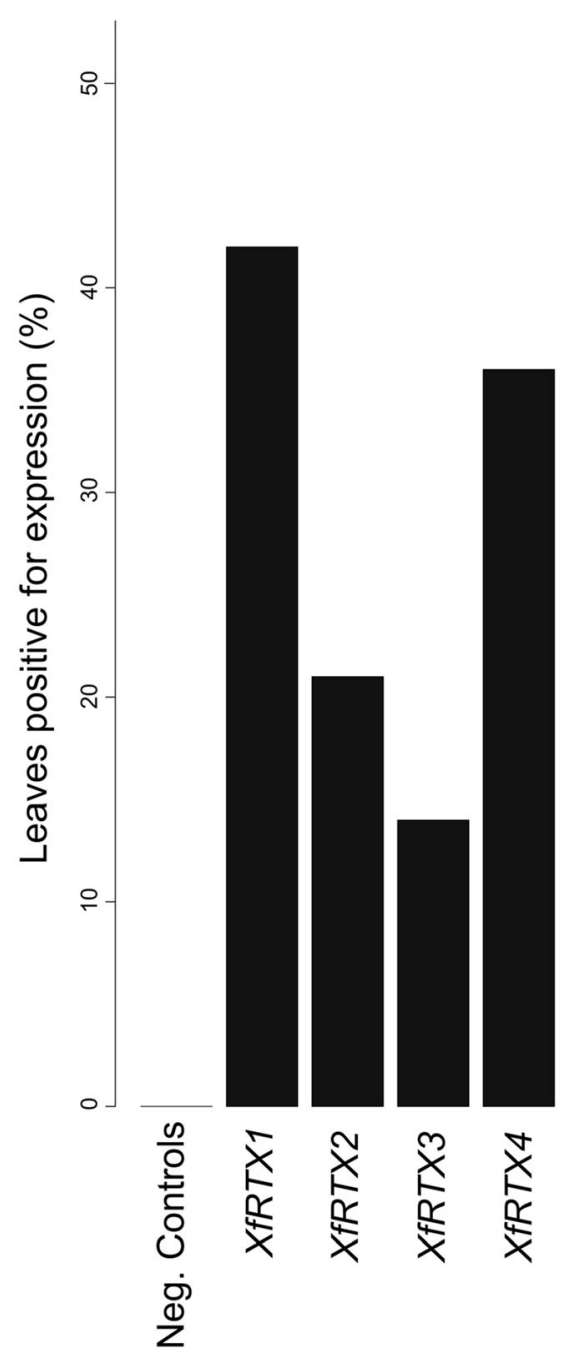

Fig. 1 In planta expression of the XfRTX genes. a Agarose gel demonstrating Xf RTX qPCR products. (+ controls), amplified from Xf (Temecula) genomic DNA, and (leaf 5), GPCR product amplified from one of the 14 leaves tested for each RTX primer pair. All qPCR products were gel purified and sequenced to confirm identity. $\mathbf{b}$ Percentage of leaves that tested positive for XfRTX expression. Negative controls were leaves taken from asymptomatic plants

series at $1 \log _{10}$ intervals as described in Gambetta et al., 2007 [13]. Each reaction $(20 \mu \mathrm{L})$ contained $250 \mathrm{nM}$ of each primer, $1 \mu \mathrm{L}$ of template DNA, and $10 \mu \mathrm{L}$ of Power SYBR Green Master Mix (Applied Biosystems). Thermal cycling conditions were as follows; $95{ }^{\circ} \mathrm{C}$ for $10 \mathrm{~min}$, 40 cycles of $95{ }^{\circ} \mathrm{C}$ for $10 \mathrm{~s}$ and $60{ }^{\circ} \mathrm{C}$ for $1 \mathrm{~min}$. Each cDNA sample was run in triplicate. Expression from symptomatic leaves was detected similarly, but with $5 \mu \mathrm{L}$ of 1:10 diluted cDNA as template. PCR products were gel purified using a Qiaquick Gel Extraction Kit (Qiagen, Inc.) following the manufacturer's protocol and then confirmed by direct sequencing. Primer only (for false positives via primer dimer) and non-reverse transcribed RNA (for false positives via residual DNA contamination) negative controls were included for all analyses.

\section{Phylogenetic and comparative analyses}

Multisequence alignments were performed using Clustal [29] and the aligned sequences were edited with the sequence editor G blocks [30]. These sequences were then submitted to phylogenetic analysis using Phylip ver3.6 (distributed by the author, Felsenstein, J., Department of Genome Sciences, University of Washington, Seattle) and distance trees using Protdist and Fitch were determined. Protein distances were calculated using the Jones, Thornton, Taylor distance matrix [31]. The dotplot analysis was performed using Dotter in the ms dos environment [32].

\section{Results}

\section{Xf RTX expression in planta}

Our attention was drawn to the $R T X$ genes from Xylella fastidosa after simple sequence examination showed that these potential pathogenicity factors appeared as a four locus gene family in all three strains but that there were unusual patterns of diversification (see below). Therefore, we set out to see if these four loci were expressed in $X f$ infected plants. Utilizing qPCR we demonstrated that all four Temecula RTXs are expressed during pathogenesis in naturally infected field grown Chardonnay grapevines. Primer pairs were developed to each Temecula $R T X$ and were validated by conventional PCR (Fig. 1, positive controls). Further, we constructed qPCR standard curves (data not shown), prepared cDNA from symptomatic leaves, and assessed $R T X$ expression in each leaf. We detected expression of RTX1, RTX2, RTX3, and RTX4, in 42, 21, 14, and 
$36 \%$ of the leaves tested, respectively (Fig. 1b). Leaves from asymptomatic controls showed no product. Products were gel isolated and sequenced to confirm their identities and proper negative controls were included to discount the possibility of false positives (see Materials and Methods).

\section{Xf RTX phylogeny}

$X f$ contains four RTX loci [28]. The gene family is relatively diverse with the homologous portions of the genes showing much greater similarity between orthologues from different strains than seen between the different paralogous loci (Fig. 2). Phylogenetic analysis of the conserved domains of the $X f$ RTXs (i.e. the coding regions excluding the hypervariable N-termini; Fig. 3) display an evolutionary pattern expected from population isolation and vertical evolution from a common $X f$ ancestor that also carried the four RTX orthologues (Fig. 2). RTX1, RTX2, and RTX3 are more closely related to each other than they are to RTX loci from other related organisms. RTX4 is more closely related to the bacteriocin RTX-like protein first described in Rhizobium leguminosarum [33]. On the other hand, the

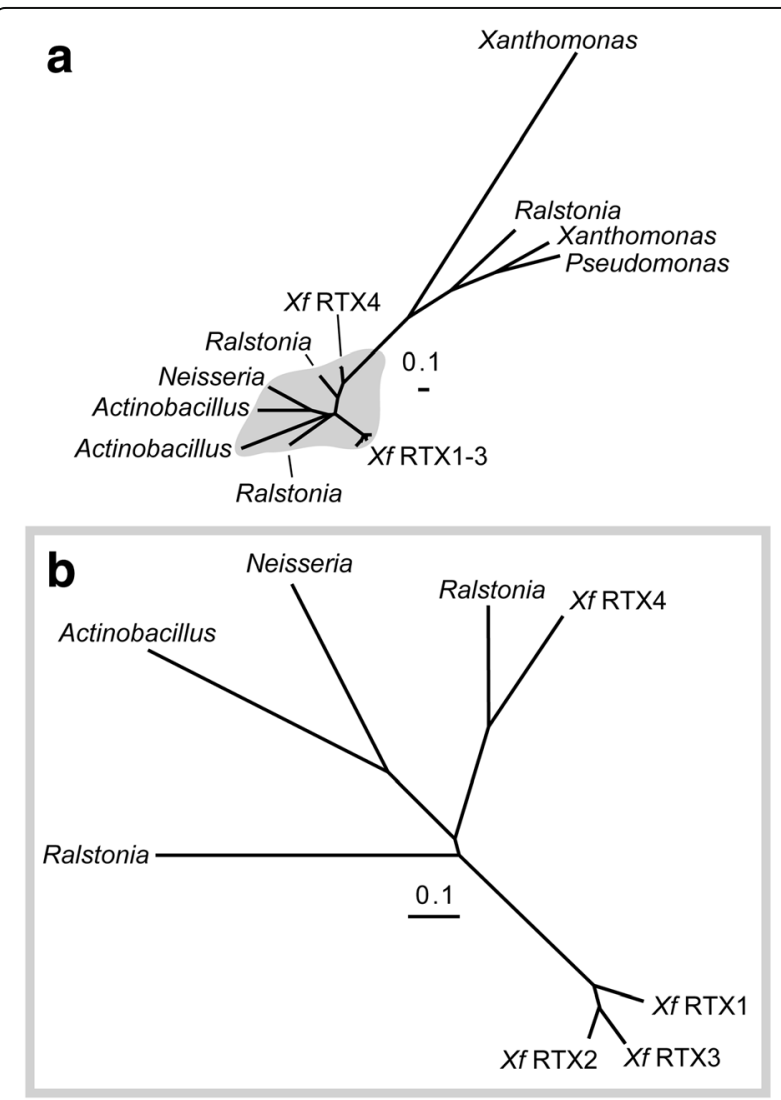

Fig. 2 a, b Unrooted dendograms demonstrating the relationship between the conserved regions (coding regions excluding the hypervariable N-termini) Xf and other related organisms' RTX peptide sequences. The Xf RTXs and the genus of the other organisms are noted. b Magnification of the shaded portion of the tree in $\mathbf{a}$. Trees were created using the Phylip ver3.6 and distance scale is shown

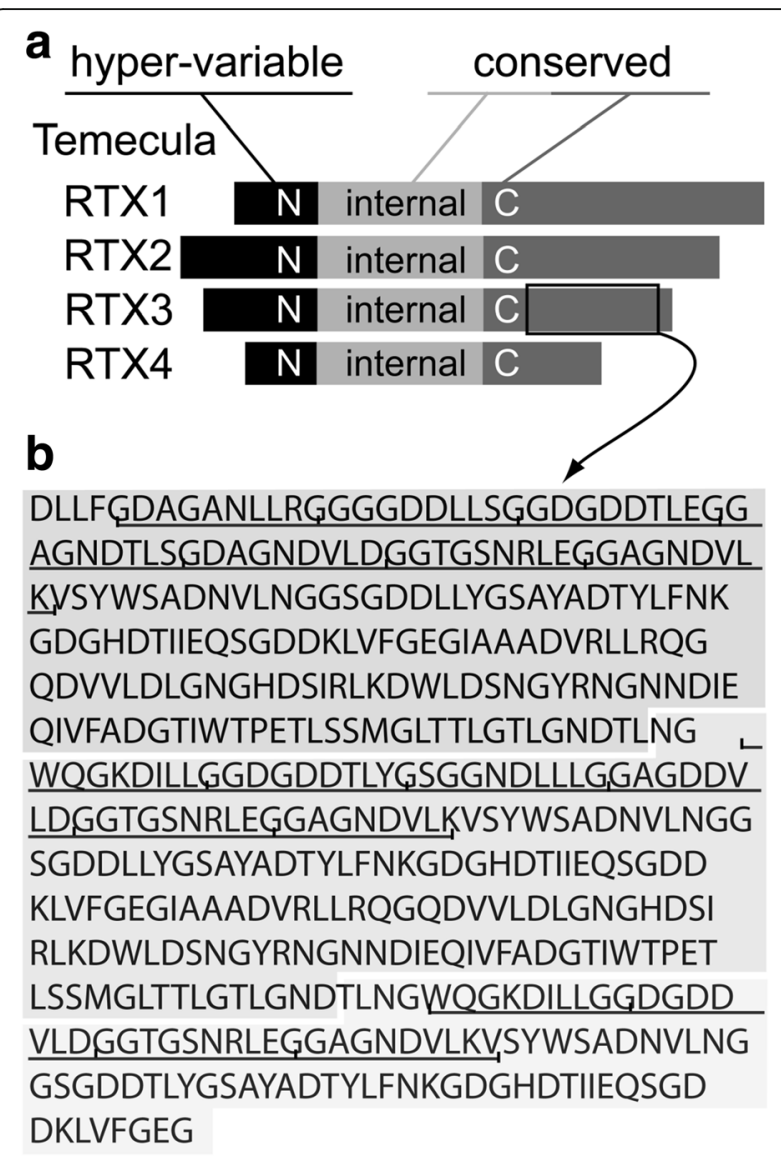

Fig. 3 Xf (Temecula) RTX proteins. a Schematic of the Temecula RTX proteins delimited into the hyper-variable $\mathrm{N}$-terminus $(\mathrm{N})$, internal sequences (internal), and C-terminus (C). For a comprehensive comparison of Temecula and 9a5c N- and C-terminal sequence identities see Table 1. b Amino acid sequence of the C-terminal region of the Temecula RTX3 protein containing the characteristic nonapeptide repeats (underlined)

$X f$ RTXs are highly diverged from RTXs from closely related Xanthamonas and Pseudomonas species. In general $X f$ RTXs are much more similar to those found in Ralstonia, Neisseria, and Actinobacillus species.

\section{Variation in the $\mathrm{N}$-terminal region of Xf RTXs}

The four $X f$ RTXs contain different $\mathrm{N}$-termini, in contrast to the remaining, highly conserved regions of the protein including the C-terminal RTX domain (Fig. 3). The hypervariable $\mathrm{N}$-termini are of variable lengths and extend from the protein start to a conserved DPL(V/A)LDLD motif. The C-terminal RTX domain is the region containing the characteristic nonapeptide repeats (Fig. 3). Within strains there is no detectable $\mathrm{N}$-terminal sequence similarity. For example, $\mathrm{N}$-terminal sequence identities between the four RTX paralogues within $X f$ Temecula range from 7 to $17 \%$, while Cterminal identities are what would be expected from orthologous genes ranging from 30 to $93 \%$ even including the more distant RTX4 (Fig. 3b and Table 1). RTX1 and RTX4 
Table 1 Sequence identities between the N-terminal and C-terminal regions of the Xf Temecula and 9a5c RTXs

\begin{tabular}{|c|c|c|c|c|c|c|c|c|c|}
\hline & & \multicolumn{8}{|c|}{ Temecula } \\
\hline & & \multicolumn{4}{|c|}{$\mathrm{N}$-terminal $^{*}$} & \multicolumn{4}{|c|}{ C-terminal $^{*}$} \\
\hline & & RTX1 & RTX2 & RTX3 & RTX4 & RTX1 & RTX2 & RTX3 & RTX4 \\
\hline \multirow[t]{4}{*}{ Temecula } & RTX1 & 100 & & & & 100 & & & \\
\hline & RTX2 & 10 & 100 & & & 75 & 100 & & \\
\hline & RTX3 & 13 & 17 & 100 & & 93 & 72 & 100 & \\
\hline & RTX4 & 13 & 16 & 7 & 100 & 35 & 31 & 30 & 100 \\
\hline \multirow[t]{4}{*}{$9 a 5 c$} & RTX1 & 12 & 10 & 10 & 11 & 91 & 72 & 85 & 32 \\
\hline & RTX2 & 10 & 91 & 17 & 16 & 92 & 72 & 87 & 29 \\
\hline & RTX3 & 16 & 18 & 91 & 7 & 85 & 74 & 86 & 29 \\
\hline & RTX4 & 14 & 16 & 17 & 26 & 32 & 28 & 32 & 90 \\
\hline
\end{tabular}

*Sequence relatedness of $\mathrm{N}$-terminal (from the start to DPL(V/A)LDLD) and C-terminal (from the first GGX motif to stop) portions of Xf RTXs. (Blosum Matrix, Gap open-1, end gap-10, gap extension 1, gap distance-10) exhibit N-terminal hyper-variability between orthologues of Temecula and 9a5c (12-26\% identity), while RTX2 and RTX3 have highly conserved N-termini (91\% identity). These differences in N-terminal homology between strains are coincident with structural differences in the operons as a whole (Additional file 1: Figures S1 and S2).

\section{Operon structure}

Through similar analyses we compared orthologous operons across all four strains (Additional file 1: Figures S1 and S2). In general, all four RTX operons share a common structure: a region of tandem duplications of a module containing various numbers of putative ORFs (referred to as a "modular repeat"), followed by the full length RTX itself (e.g. Fig. 4a, Additional file 1: Figures S1 and S2). All ORFs contain putative -35 sequences and Pribnow-Schaller boxes at their 5 " ends.

The RTX2 and RTX3 operons are similar across all strains, exhibiting regular tandem duplication of a modular repeat containing two putative ORFs lying

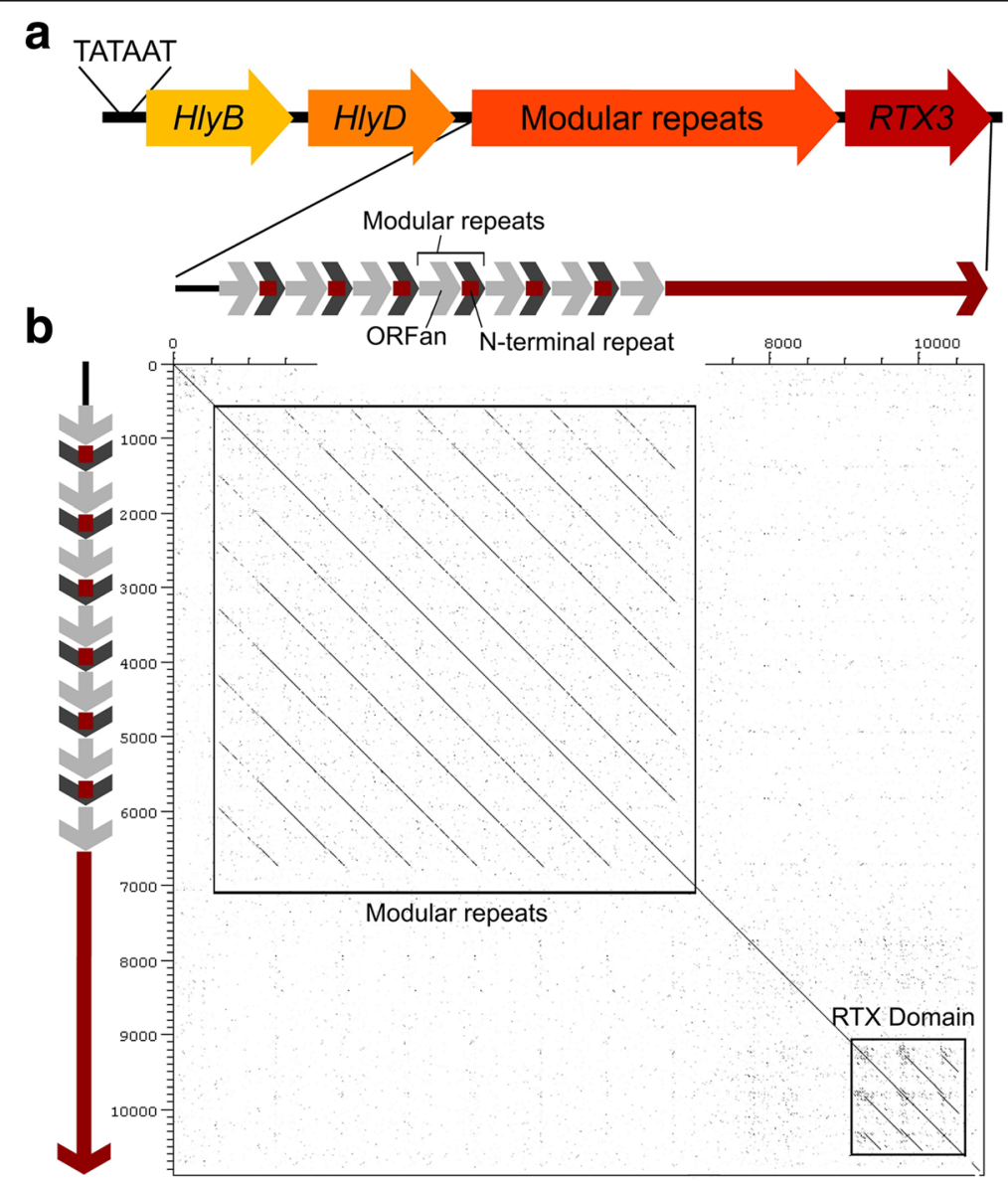

Fig. 4 Structure of the Xf (Temecula) RTX3 operon. a The RTX3 coding region is preceded by the modular repeats, HlyB and HlyD genes, and the Pribnow-Schaller box (TATAAT). $\mathbf{b}$ DNA-DNA dot plot (created with the Dotter software) representing a self-comparison of the modular repeats and RTX3 coding region. The Temecula RTX3 operon contains six modular repeats including the N-terminal repeats (red) and ORFans (grey); arrows of the same color are homologous 
upstream of the full length RTX (e.g. Figs. 4 and 5). One of the ORFs is nearly identical to the N-terminus of the full length RTX (the N-terminal repeats) while the other is an ORFan, in that it shares no homology with any protein in published databases. For example, a DNADNA dot plot comparing the Temecula RTX3 operon with itself illustrates the modular repeats in the $5^{\prime}$ portion of the operon (Fig. 4b). All strains differed in the number of modular repeats. The RTX1 and RTX4 operons have a more complex structure, with a short $\mathrm{N}$-terminal repeat interspersed among clusters of ORFans. In some cases these clusters of ORFans are duplicated, in some cases rearranged, but the ORFs themselves remain intact and conserved.

Ann1 RTX1 and Dixon RTX3 both contain premature stop codons. Copies of the modular repeat in the Ann1 and Dixon RTX2 operons are frame shifted and contain a premature stop codon, respectively, and a modular repeat in the Ann1 RTX3 operon is frame shifted (Additional file 1: Figures S1 and S2).

\section{The modular repeats}

The modular repeats in the RTX2 and RTX3 operons show little variation across strains. The individual

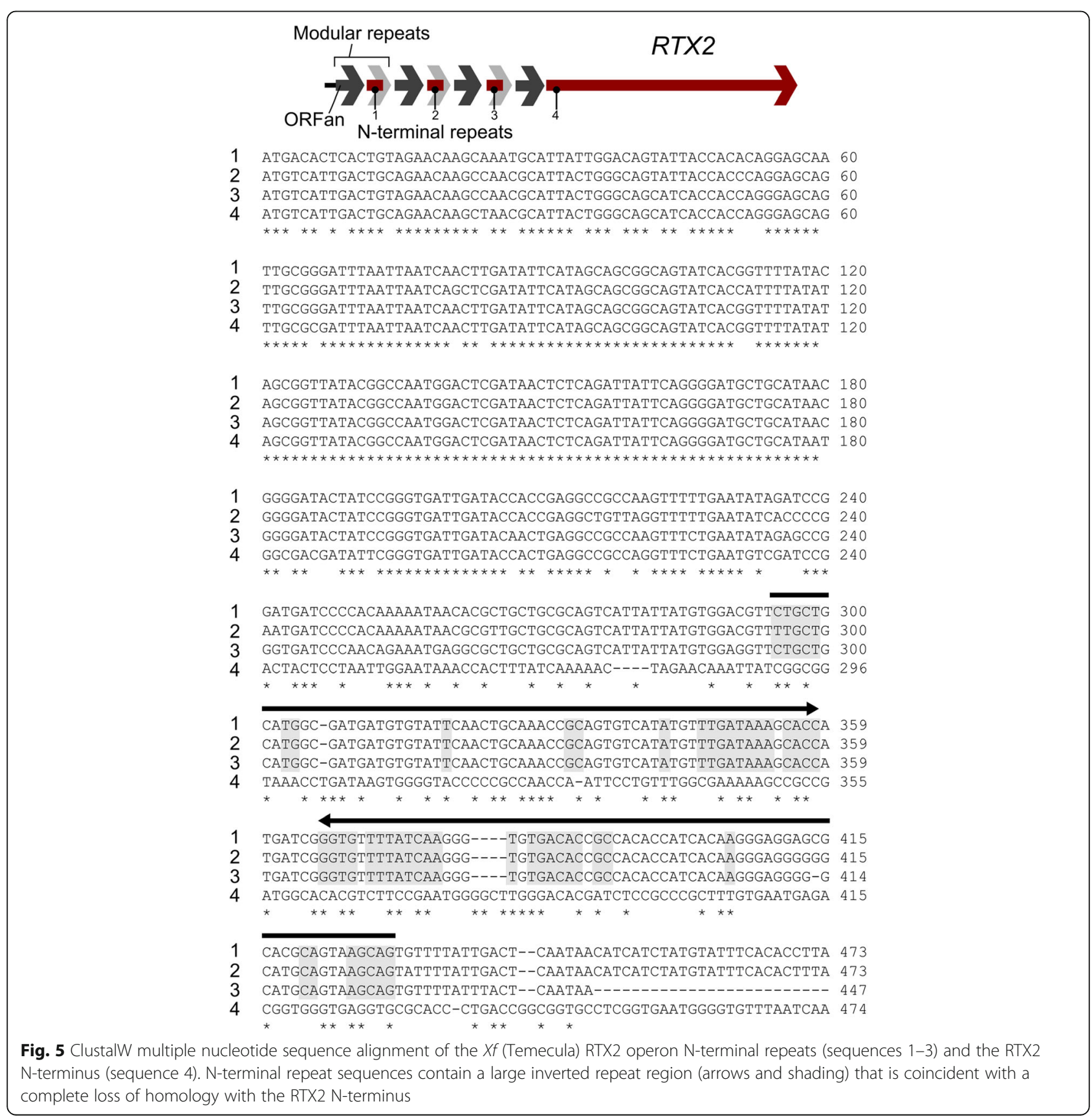


modular repeats are highly conserved, and the loss of sequence similarity between the $\mathrm{N}$-terminal repeat and the full length RTX is abrupt (Fig. 5). This conservation of sequences between the $\mathrm{N}$-terminal repeat and the $\mathrm{N}$-terminus of the corresponding RTX, followed by no observable similarity between the remaining module sequences and the remaining 3'end of the RTX gene is the classical signature of a gene fusion, or what is also referred to as a mosaic genetic pattern.

In the RTX1 and RTX4 the pattern of the modular repeats are more complicated and there is more variation between modules. Some modules resemble the RTX $\mathrm{N}$-terminus-ORFan pattern seen in the RTX2 and RTX3 operons while others are either shorter or even completely different. Surprisingly, some of the N-terminal repeats are most similar not to their corresponding full length RTX, but to the N-termini of RTXs from other $X f$ strains, and even other organisms (Fig. 6). For example, the Temecula RTX1 operon contains two short N-terminal repeat fragments, one sharing homology to its corresponding RTX, and another nearly identical to the non-homologous
N-terminus of 9a5c RTX1 (Fig. 6a). The Ann1 and Dixon RTX4 operons contain an N-terminal repeat whose closest relative is the N-terminus of a RTX from Ralstonia solanacearum (Fig. 6b), a bacterium only remotely related to $X f$.

\section{Inverted repeats, Rhs-like sequences, and GC content of the modules}

The modular repeats of the RTX2 and RTX3 operons contain inverted repeat sequences. In the RTX2 operon an inverted repeat spans a large portion of the 3' end of the ORFan (Fig. 5). The RTX3 modular repeat also has a smaller inverted repeat sequence (Additional file 1: Figure S3). In both case the repeat structures lie close to the homology discontinuity when the modular repeats are aligned with the adjacent full length RTX (Fig. 5 and Additional file 1: Figure S3). Such inverted repeats are often associated with special recombination or transposition activities that may very well be a part of the underlying mechanism that is producing the modular and mosaic patterns we are describing here.
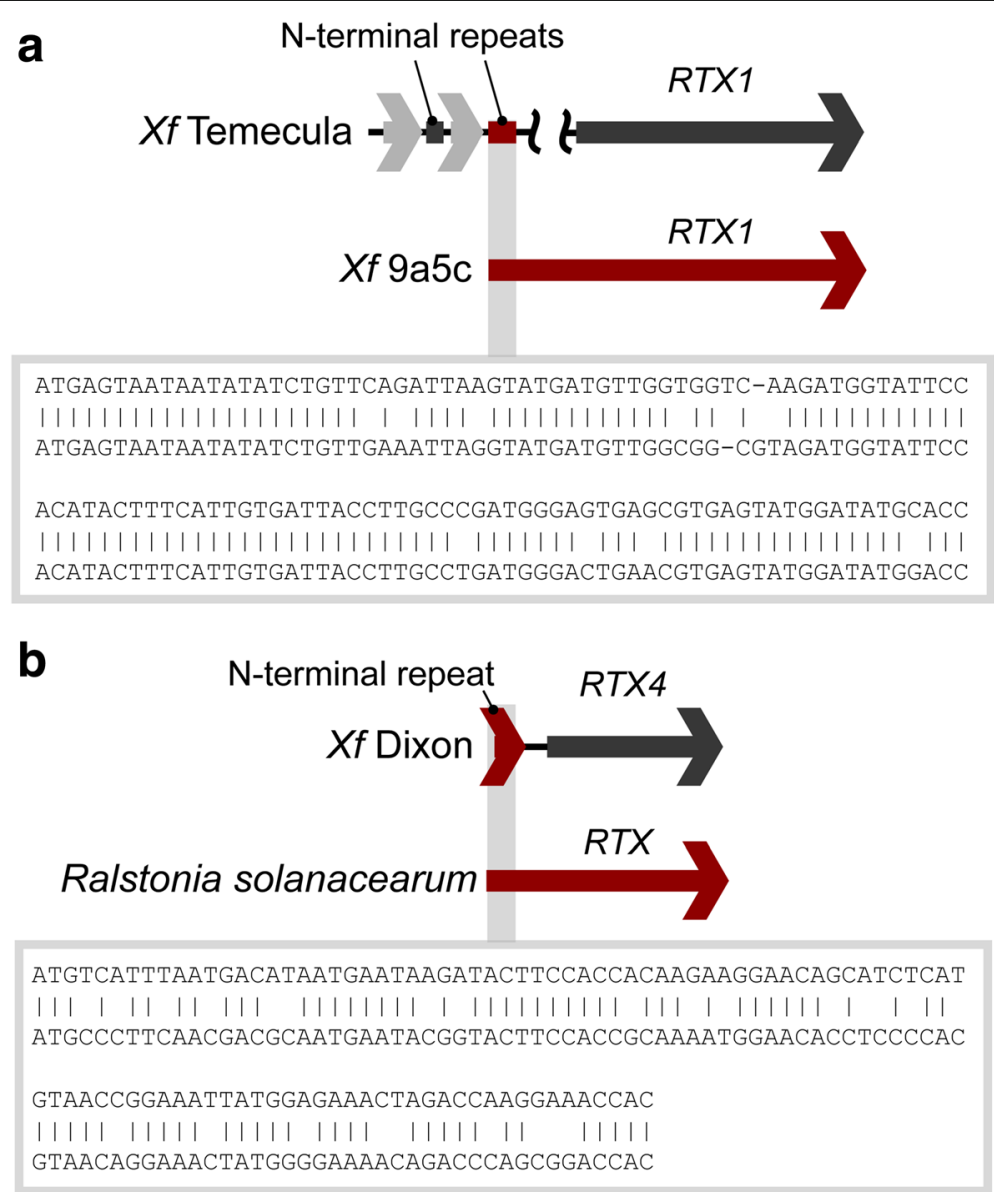

Fig. 6 Nucleotide sequence alignments of N-terminal repeats with homology to other Xf strains and other organisms. a The Xf (Temecula) RTX1 operon contains an N-terminal repeat homologous to the N-terminus of RTX1 from strain 9a5c. b The Xf (Dixon) RTX4 operon contains an N-terminal repeat homologous to the N-terminus of RTX4 from Ralstonia solanacearum 
The modular repeats within the RTX1 and RTX4 operons were different. For example, the Temecula RTX4 operon contains a small N-terminal repeat, unique to this $X f$ strain, that shares homology to the $E$. coli Rhs protein family (E values of approximately $10^{-5}$ ) (Fig. 7). This ORF also exhibits a mosaic genetic pattern, with an abrupt transition from sequences homologous to Rhs to those homologous to the full length RTX.

The modular repeats at the 5'ends of the four RTX operons display many patterns expected of mobile genetic elements (e.g. involvement in mosaic patterns and linkage to sequences that appear to be involved in heterologous recombination mechanisms). In addition, GC content of these modular repeats have low GC content $(41-44 \%)$ when compared to the rest of the $X f$ genome $(52.7 \%$, [28]) or even to the rest of the RTX operon (54\%). Reduced GC content like this is a signature of DNA involved in horizontal gene transfer [34].

\section{Discussion}

\section{Xf RTX expression in planta}

To date there has been no direct evidence implicating the $X f$ RTXs in pathogenesis. In this study we demonstrated that all four genes are expressed during pathogenesis in grapevine. However, $X f R T X$ expression was not detected in all the leaves tested possibly due to the patchy distribution of $X f$ in planta [13] or alternatively because they may be expressed only under particular conditions, or during specific developmental time frames. We did not quantify expression of the XfRTXs in culture and thus they may be constitutively expressed.

In general, the approach utilized in this study suffers from the limitation that total mRNA, derived from both the plant and $X f$, is being isolated. Thus, $X f$ concentrations and/or $X f R T X$ expression must be great enough to overcome dilution resulting from plant derived message. It is for this reason that despite utilizing a qPCR based detection method we did not present quantitative data in this study. Future quantification of gene expression and its relation to $X f$ concentrations in planta should utilize an existing immunocapture or related technique in order to enrich for $X f$ derived message.

\section{Genetic exchange and operon structure}

The direct modular repeats at the $5^{\prime}$ end of the RTX operon have many of the hallmarks of mobile genetic elements: (1) The inverted repeated sequences flanking the module in RTX2 and 3 and the appearance of an rhs sequence at a modular junction in RTX4 are features that are associated with known mobile genetic elements from insertion sequences to pathogenicity islands. (2) The GC content of the modules averages approximately $44 \%$, significantly lower than the GC content of the $X f$ genome. Regions of lowered GC content are a near universal signal of mobile genetic elements from those as small as insertion sequences to large pathogenicity islands, reflecting the heterologous DNA recombination

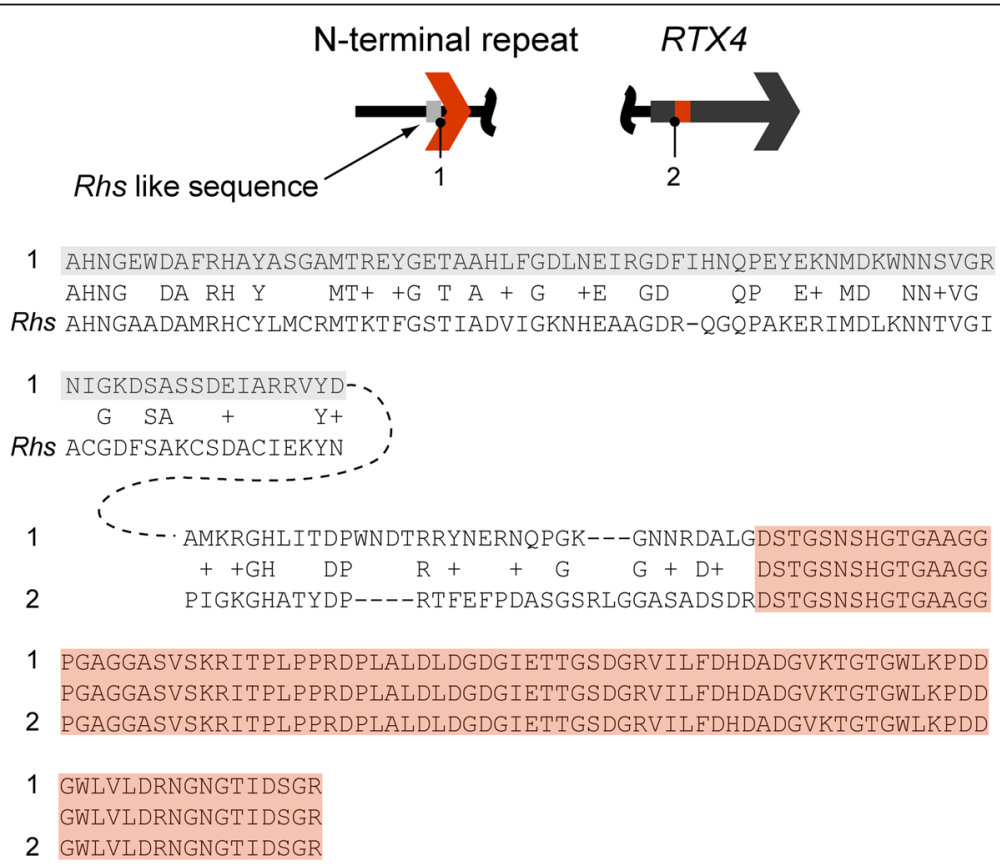

Fig. 7 The Xf (Temecula) RTX4 operon N-terminal repeat (sequence 1) is a chimera between sequences with homology to Rhs sequences (grey shading) and the RTX4 N-terminus (orange shading). The aligned Rhs sequence is from Escherichia coli (NCBI Accession YP_001461405). Alignments are split but the $\mathrm{N}$-terminal repeat sequence is continuous (dotted line) 
events during their histories [34]. (3) One of the modules in RTX4 has its closest relative in Ralstonia, though the sequence is completely absent in two of the $X f$ strains as well as $X f$ 's closer relatives. And, (4) the RTX genes appear as mosaics.

\section{$X f$ RTXs; protein mosaics}

The $X f$ RTXs are protein mosaics with their hypervariable $\mathrm{N}$-termini creating non-homologues at the $\mathrm{N}$ terminus and true orthologues at the C-terminus. This is consistent with the modular nature of these proteins along with their distinct functional domains that have been noted before. For example the structure of the $L e$ gionella pneumophila RTX gene suggests recombination has resulted in tandem duplications of some domains; reminiscent of the $X f$ RTX operon structure characterized in this study [35], but this is the first example where the hypervariable $\mathrm{N}$-terminal portion of the protein is included in the repeat. The precise mechanisms that bring about the mosaic structure in many RTX proteins are unknown, but in some cases there is clear evidence that the genes encoding these proteins have evolved through horizontal gene transfer from both within and between species (discussed below). The large diversity of biochemical functions attributed to RTXs is likely related to the mosaic structure of RTX proteins. To what extent this uncharacterized N-terminal protein domain, and the genetic exchanges therein, contribute to $X f$ pathogenesis or host specificity is unknown, but worthy of future investigation.

\section{RTX genes, ORFans, and horizontal gene transfer}

In general the $X f$ RTX loci and their individual modules show evidence of being involved horizontal gene transfer events. The majority of $X f$ 's closer relatives, the gamma proteobacterum Xanthamonas and Pseudomonas species do not contain RTXs, and those that do contain highly divergent proteins. The most closely related Xanthamonas RTX, from Xanthamonas axonopodis, also appears to have been acquired horizontally [36], and there are numerous other cases in which the acquisition of RTXs appears to have occurred through horizontal gene transfer; the Mannheimia (Pasteurella) haemolytica leukotoxins [37-39], a thermostable hemolysin among Vibrio species [40], and the Vibrio cholera RTX [41], among others. Furthermore, like the $X f$ RTXs characterized here, RTX coding regions in some other organisms are associated with mobile genetic elements such as Rhs/vgr sequences [41, 42] and plasmids [43].

ORFans (called "orphans" when described in Eukarkotic genomics literature) are open reading frames that have been found in whole genome sequences that have no identifiable homologs in other, even very closely related, taxonomic groups. Given that there is no sequence homology within the protein database's these are almost by definition of unknown function. These ORFs are not simple sequencing artifacts but represent real genes that are expressed and contribute to organismal phenotype [44]. At this point the simplest explanation is that they are recently evolved genes, at least since the last bifurcation from the given taxa's last common ancestor. $X f$ RTX4 in our study of $X f$ looks like an ORFan but one homolog is found in a distantly related Ralstonia strain suggesting a horizontal gene transfer of a recently evolved gene into another species that occupies a similar habitat. We may speculate that Xf RTX4 plays an important role in pathogenesis.

That the $X f$ RTXs appear more closely related to those from the beta proteobacterium Ralstonia solanacearum is noteworthy since Ralstonia is also a vascular plant pathogen. Given the cytolytic effects of RTXs in other pathogenic bacteria a similar role in plant pathogenesis is plausible, especially considering these organisms' niche environment; the non-living, nutrient poor, water conducting xylem. A cytolytic function, by which the pathogen manipulates it's environment to make it more hospitable through obtaining nutrients from the surrounding, living, xylem parenchyma, would address the perplexing observation that they grow to such high densities in such a poor environment. Furthermore, it would reconcile the prevailing idea that pathogenesis results from vascular occlusion and water deficit with more contemporary studies questioning this hypothesis. As with cellular level water deficits, loss of membrane integrity leads to decreases in both water potential and turgor. The difference however is that loss of membrane integrity would lead to increases in solute potential (as opposed to decreases during cellular dehydration), which is what is observed during $X f$ pathogenesis $[15,45]$. Here we provide evidence that genetic exchanges have occurred with Ralstonia solanacearum suggesting that their common niche environment may facilitate, and even favor, gene flow between the two organisms.

A variety of bacterial plant pathogens harbor genes encoding RTXs and this work provides the first steps investigating their role in pathogenesis. The uncanny similarities in structure and the high prevalence of genetic exchange (probably horizontally) in both plant and animal pathogen RTXs suggests they may play key roles in pathogenesis across kingdoms.

\section{Conclusions}

RTXs are pathogenicity factors, widespread among gram-negative bacterial pathogens. To date, studies investigating the role of RTXs in pathogenesis have primarily focused on their effects in animal cells and tissues. This study provides the first direct evidence of their expression during pathogenesis in grapevine during 
Pierce's disease. Through detailed sequence comparisons we show that the $X f$ RTX operons have a unique structure suggesting that the modular repeats that make up a large portion of these operons are novel mobile genetic elements.

\section{Additional file}

Additional file 1: Table S1. Gene name, NCBI protein accession number, and NCBl gene locus tag for the Xylella fastidiosa RTXs. Figure S1 and S2. Complete DNA-DNA dot plots (created with the Dotter software) of RTX operon comparisons between Xf (Temecula) and itself, other Xf strains Dixon, 9a5c, and Ann1, and in the case of the RTX4 operon Ralstonia solanacearum. Putative open reading frames are designated by arrows, orthologues are like colored, and mutations resulting in premature stop codons or frame shifts (FS) are noted. Figure S3. ClustalW multiple nucleotide sequence alignment of the Xf (Temecula) RTX3 operon N-terminal repeats (sequences 1-6) and the RTX3 N-terminus (sequence 7). N-terminal repeat sequences contain a large inverted repeat region (arrows and shading). (PDF $809 \mathrm{~kb}$ )

\section{Acknowledgments}

The authors would like to thank Dr. David Mills for providing the necessary instrumentation for the GPCR studies, and Ryan Leininger and Beringer Vineyards for facilitating the field studies.

\section{Funding}

This work was funded by the California Department of Food and Agriculture, agreement no. 01-0712, and USDA-CREES, grant no. 2005-34442-15841. The funding bodies themselves were not involved in the design of the study or the collection, analysis, and interpretation of data, or in writing the manuscript.

\section{Availability of data and materials}

All data analyzed in this study are available from NCBI, https:// www.ncbi.nlm.nih.gov/. Accession numbers can be found in Additional file 1: Table S1.

\section{Authors' contributions}

GAG, MAM, and MS conceived of and designed all experiments and analyses. GAG carried out PCR experimentation and bioinformatics analyses except for tree construction which was done by MS. GAG, MAM, and MS all participated in the writing and editing of the manuscript. All authors read and approved the final manuscript.

\section{Ethics approval and consent to participate}

Not applicable.

\section{Competing interests}

The authors declare that they have no competing interests.

\section{Publisher's Note}

Springer Nature remains neutral with regard to jurisdictional claims in published maps and institutional affiliations.

\section{Author details}

'Bordeaux Science Agro, Institut des Sciences de la Vigne et du Vin, Ecophysiologie et Génomique Fonctionnelle de la Vigne, UMR 1287, F33140 Villenave d'Ornon, France. ${ }^{2}$ Department of Viticulture and Enology, University of California, Davis, CA 95616-8645, USA. ${ }^{3}$ Department of Medical Microbiology and Immunology, School of Medicine, University of California, Davis, CA 95616-8645, USA.
Received: 8 August 2017 Accepted: 26 April 2018

Published online: 04 May 2018

\section{References}

1. Binnewies TT, Motro Y, Hallin PF, Lund O, Dunn D, La T, et al. Ten years of bacterial genome sequencing: comparative-genomics-based discoveries. Funct Integr Genomics. 2006;6:165-85.

2. Danin-Poleg Y, Somer L, Cohen LA, Diamant E, Palti Y, Kashi Y. Towards the definition of pathogenic microbe. Int J Food Microbiol. 2006;112:236-43.

3. Yang F, Yang J, Zhang X, Chen L, Jiang Y, Yan Y, et al. Genome dynamics and diversity of Shigella species, the etiologic agents of bacillary dysentery. Nucleic Acids Res. 2005;33:6445-58

4. Amavisit $P$, Lightfoot D, Browning GF, Markham PF. Variation between pathogenic serovars within Salmonella pathogenicity islands. J Bacteriol. 2003:185:3624-35. American Society for Microbiology (ASM)

5. Bhattacharyya A, Stilwagen S, Ivanova N, D'Souza M, Bernal A, Lykidis A, et al. Whole-genome comparative analysis of three phytopathogenic Xylella fastidiosa strains. Proc Natl Acad Sci. 2002:99:12403-8.

6. Bhattacharyya A, Stilwagen S, Reznik G, Feil H, Feil WS, Anderson I, et al. Draft sequencing and comparative genomics of Xylella fastidiosa strains reveal novel biological insights. Genome Res. 2002;12:1556-63. Cold Spring Harbor Laboratory Press

7. Harakava R, Gabriel DW. Genetic differenqces between two strains of Xylella fastidiosa revealed by suppression subtractive hybridization. Appl Environ Microbiol. 2003;69:1315-9.

8. Koide T, Zaini PA, Moreira LM, Vêncio RZN, Matsukuma AY, Durham AM, et al. DNA microarray-based genome comparison of a pathogenic and a nonpathogenic strain of Xylella fastidiosa delineates genes important for bacterial virulence. J Bacteriol. 2004:186:5442-9.

9. Van Sluys MA, de Oliveira MC, Monteiro-Vitorello CB, Miyaki CY, Furlan LR, Camargo LEA, et al. Comparative analyses of the complete genome sequences of Pierce's disease and citrus variegated chlorosis strains of Xylella fastidiosa. J Bacteriol. 2003;185:1018-26.

10. Hopkins DL, Purcell AH. Xylella fastidiosa : cause of Pierce's disease of grapevine and other emergent diseases. Plant Dis. 2002;86:1056-66.

11. Hopkins DL. Xylella Fastidiosa: xylem-limited bacterial pathogen of plants. Annu Rev Phytopathol. 1989:27:271-90. Annual Reviews 4139 El Camino Way, P.O. Box 10139, Palo Alto, CA 94303-0139, USA

12. Purcell AH, Hopkins DL. Fastidious xylem-limited bacterial plant pathogens. Annu Rev Phytopathol. 1996;34:131-51.

13. Gambetta GA, Fei J, Rost TL, Matthews MA. Leaf scorch symptoms are not correlated with bacterial populations during Pierce's disease. J Exp Bot. 2007;58:4037-46.

14. Thorne ET, Stevenson JF, Rost TL, Labavitch JM, Matthews MA. Pierce's disease symptoms: comparison with symptoms of water deficit and the impact of water deficits. Am J Enol Vitic. 2006;57:1-11.

15. Choat B, Gambetta GA, Wada H, Shackel KA, Matthews MA. The effects of Pierce's disease on leaf and petiole hydraulic conductance in Vitis vinifera cv. Chardonnay. Physiol Plant. 2009;136:384-94.

16. Welch RA. RTX toxin structure and function: a story of numerous anomalies and few analogies in toxin biology. Curr Top Microbiol Immunol. 2001:257:85-111.

17. Welch RA. Pore-forming cytolysins of gram-negative bacteria. Mol Microbiol. 1991;5:521-8.

18. Jeyaseelan S, Kannan MS, Briggs RE, Thumbikat P, Maheswaran SK. Mannheimia haemolytica Leukotoxin activates a nonreceptor tyrosine kinase signaling Cascade in bovine leukocytes, which induces biological effects. Infect Immun. 2001;69:6131-9.

19. Fullner KJ, Mekalanos JJ. In vivo covalent cross-linking of cellular actin by the Vibrio cholerae RTX toxin. EMBO J. 2000;19:5315-23.

20. Chang JH, Desveaux D, Creason AL. The ABCs and 123s of bacterial secretion systems in plant pathogenesis. Annu Rev Phytopathol. 2014; 52:317-45.

21. Roper MC, Burbank LP, Williams K, Viravathana P, Tien H-Y, von Bodman S. A large repetitive RTX-like protein mediates water-soaked lesion development, leakage of plant cell content and host colonization in the Pantoea stewartii subsp. stewartii Pathosystem. Mol Plant-Microbe Interact. 2015;28:1374-82.

22. Guilhabert MR, Kirkpatrick BC. Identification of Xylella fastidiosa Antivirulence genes: hemagglutinin Adhesins contribute to $X$. fastidiosa biofilm maturation and colonization and attenuate virulence. Mol Plant-Microbe Interact. 2005;18:856-68. 
23. Voegel TM, Warren JG, Matsumoto A, Igo MM, Kirkpatrick BC. Localization and characterization of Xylella fastidiosa haemagglutinin adhesins. Microbiology. 2010;156:2172-9.

24. Zhang S, Chakrabarty PK, Fleites LA, Rayside PA, Hopkins DL, Gabriel DW. Three new Pierce's disease pathogenicity effectors identified using Xylella fastidiosa biocontrol strain EB92-1. PLoS One. 2015;10:e0133796. Arnold DL, editor

25. Smolka MB, Martins-de-Souza D, Martins D, Winck FV, Santoro CE, Castellari $\mathrm{RR}$, et al. Proteome analysis of the plant pathogen Xylella fastidiosa reveals major cellular and extracellular proteins and a peculiar codon bias distribution. Proteomics. 2003;3:224-37.

26. Reddy JD, Reddy SL, Hopkins DL, Gabriel DW. TolC is required for pathogenicity of Xylella fastidiosa in Vitis vinifera grapevines. Mol PlantMicrobe Interact. 2007;20:403-10.

27. Koronakis V, Eswaran J, Hughes C. Structure and function of TolC: the bacterial exit duct for proteins and drugs. Annu Rev Biochem. 2004;73:467-89.

28. Setubal JC, Simpson AJG, Reinach FC, Arruda P, Abreu FA, Acencio M, et al. The genome sequence of the plant pathogen Xylella fastidiosa. The Xylella fastidiosa consortium of the Organization for Nucleotide Sequencing and Analysis. Nature. 2000;406:151-7.

29. Thompson JD, Higgins DG, Gibson TJ. CLUSTAL W: improving the sensitivity of progressive multiple sequence alignment through sequence weighting, position-specific gap penalties and weight matrix choice. Nucleic Acids Res. 1994;22:4673-80.

30. Castresana J. Selection of conserved blocks from multiple alignments for their use in phylogenetic analysis. Mol Biol Evol. 2000;17:540-52.

31. Jones DT, Taylor WR, Thornton JM. The rapid generation of mutation data matrices from protein sequences. Comput Appl Biosci. 1992;8:275-82.

32. Sonnhammer EL, Durbin R. A dot-matrix program with dynamic threshold control suited for genomic DNA and protein sequence analysis. Gene. 1995; 167:GC1-10.

33. Oresnik IJ, Twelker S, Hynes MF. Cloning and characterization of a rhizobium leguminosarum gene encoding a bacteriocin with similarities to RTX toxins. Appl Environ Microbiol. 1999;65:2833-40.

34. Syvanen M. Horizontal gene transfer: evidence and possible consequences. Annu Rev Genet. 1994;28:237-61.

35. D'Auria G, Jiménez N, Peris-Bondia F, Pelaz C, Latorre A, Moya A. Virulence factor rtx in legionella pneumophila, evidence suggesting it is a modular multifunctional protein. BMC Genomics. 2008;9:14.

36. Moreira LM, De Souza RF, Digiampietri LA, Da Silva ACR, Setubal JC. Comparative analyses of Xanthomonas and Xylella complete genomes. Omi A J Integr Biol. 2005;9:43-76.

37. Davies RL, Campbell S, Whittam TS. Mosaic structure and molecular evolution of the leukotoxin operon (IktCABD) in Mannheimia (Pasteurella) haemolytica, Mannheimia glucosida, and Pasteurella trehalosi. J Bacteriol. 2002;184:266-77.

38. Davies RL, Whittam TS, Selander RK. Sequence diversity and molecular evolution of the Leukotoxin (IktA) gene in bovine and ovine strains of Mannheimia (Pasteurella) haemolytica. J Bacteriol. 2001;183:1394-404.

39. Kelley ST, Cassirer EF, Weiser GC, Safaee S. Phylogenetic diversity of Pasteurellaceae and horizontal gene transfer of leukotoxin in wild and domestic sheep. Infect Genet Evol. 2007;7:13-23.

40. Terai A, Baba K, Shirai H, Yoshida O, Takeda Y, Nishibuchi M. Evidence for insertion sequence-mediated spread of the thermostable direct hemolysin gene among Vibrio species. J Bacteriol. 1991;173:5036-46.

41. Sheahan K-L, Cordero CL, Satchell KJF. Identification of a domain within the multifunctional Vibrio cholerae RTX toxin that covalently cross-links actin. Proc Natl Acad Sci U S A. 2004;101:9798-803.

42. Wang YD, Zhao S, Hill CW. Rhs elements comprise three subfamilies which diverged prior to acquisition by Escherichia coli. J Bacteriol. 1998;180:4102-10

43. Boerlin P, McEwen SA, Boerlin-Petzold F, Wilson JB, Johnson RP, Gyles CL. Associations between virulence factors of Shiga toxin-producing Escherichia coli and disease in humans. J Clin Microbiol. 1999:37:497-503.

44. Neme R, Tautz D. Evolution: dynamics of De novo gene emergence. Curr Biol. 2014;24:R238-40.

45. Goodwin PH, DeVay JE, Meredith CP. Physiological responses of Vitis vinifera cv. "Chardonnay" to infection by the Pierce's disease bacterium. Physiol Mol Plant Pathol. 1988;32:17-32.

\section{Ready to submit your research? Choose BMC and benefit from:}

- fast, convenient online submission

- thorough peer review by experienced researchers in your field

- rapid publication on acceptance

- support for research data, including large and complex data types

- gold Open Access which fosters wider collaboration and increased citations

- maximum visibility for your research: over $100 \mathrm{M}$ website views per year

At BMC, research is always in progress.

Learn more biomedcentral.com/submissions 